\title{
Measurement of gastric emptying time by ultrasonography
}

\author{
Bailong $\mathrm{Hu}^{1} \cdot$ Haiyan $\mathrm{Zhou}^{2} \cdot \mathrm{Xiaohua} \mathrm{Zou}^{1}$ (]) \\ Received: 10 December 2019 / Accepted: 4 January 2020 / Published online: 20 January 2020 \\ (c) Japanese Society of Anesthesiologists 2020
}

Keywords Pupil size $\cdot$ Hypotension $\cdot$ General anesthesia

To the editor:

We have read with great interest the recently published article by Sugita et al. [1], which investigated gastric emptying times after a normal Japanese breakfast containing various types of foods in healthy adult volunteers using ultrasonography. The authors showed that the gastric volume (GV) from the gastric antral area after $8 \mathrm{~h}$ fasting was $53.1 \mathrm{ml}$ and the gastric emptying time was $276.4 \pm 58.9 \mathrm{~min}$. We appreciate the authors on their efforts. However, we found a flaw that calls the findings into question.

In the method section, the authors stated that GV was obtained using an existing model validated in adults as follows:

$\mathrm{GV}(\mathrm{ml})=27.0+146 \times \mathrm{CSA}\left(\mathrm{cm}^{2}\right)-1.28 \times$ age $($ year $)$.

However, according to the original literature [2] quoted by the authors, the correct formula for calculating GV is as follows:

$\mathrm{GV}(\mathrm{ml})=27.0+14.6 \times \mathrm{CSA}\left(\mathrm{cm}^{2}\right)-1.28 \times$ age $($ year $)$.

Obviously, we will overestimate the GV if we use the wrong formula provided by Sugita et al. For example, a CSA

Bailong $\mathrm{Hu}$ and Haiyan Zhou contributed equally to the letter.

This comment refers to the article available online at https://doi. org/10.1007/s00540-020-02734-6.

Xiaohua Zou

409017612@qq.com

Bailong $\mathrm{Hu}$

409017612@qq.com

1 Department of Anesthesiology, The Affiliated Hospital of Guizhou Medical University, No. 28 Guiyi Street, Yunyan District 550004, Guiyang, China

2 Department of Clinical Reseach Centre, The Affiliated Hospital of Guizhou Medical University, No. 28 Guiyi Street, Yunyan District 550004, Guiyang, China of $10 \mathrm{~cm}^{2}$ corresponds to a $1448 \mathrm{ml}$ of $\mathrm{GV}$ in a 30-year-old patient using the wrong formula, but in fact only $134 \mathrm{ml}$ of GV in a 30-year-old patient using the correct formula. Hence, we here are wondering whether the mistake was just a clerical error. We also believe that this kind of error should not exist in the scientific journal.

Funding None.

\section{Compliance with ethical standards}

Conflicts of interest None.

\section{References}

1. Sugita M, Matsumoto M, Tsukano Y, Fukunaga C, Yamamoto T. Gastric emptying time after breakfast in healthy adult volunteers using ultrasonography. J Anesth. 2019;33(6):697-700.

2. Van de Putte P, Perlas A. Ultrasound assessment of gastric content and volume. Br J Anaesth. 2014;113(1):12-22.

Publisher's Note Springer Nature remains neutral with regard to jurisdictional claims in published maps and institutional affiliations. 